\title{
Culture-based Social support to Older Adults in Nnewi, South-East Nigeria Samuel O. Ebimgbo ${ }^{1}$, Christy N. Obi-Keguna ${ }^{1}$, Ngozi E. Chukwu ${ }^{1}$, Chinyere E. Onalu ${ }^{1}$, Sunday E. Abonyi ${ }^{2}$ \& Uzoma O. Okoye ${ }^{1}$
}

\author{
${ }^{1}$ Department of Social Work, University of Nigeria, Nsukka, Nigeria \\ ${ }^{2}$ Department of Sociology, Caritas University Amorji-Nike, Enugu State \\ Email: chinyere.onalu@unn.edu.ng
}

\begin{abstract}
Background: Old age usually comes with frailty and withdrawal resulting to dependence on various support systems for assistance. However, studies have shown that social support available for older adults from these support systems especially in south-east Nigeria is inadequate. This study therefore depicts some cultural activities as a form of social support system for older adults.

Data and methods: Focus group discussions and in-depth interviews were conducted with 40 older adults and their caregivers. Thematic analytic approach was adopted to analyse the data.

Findings: Some of the prevailing cultural activities including village meetings, marriage ceremonies, child naming or dedications, funerals, postpartum care serve as veritable means of support to older adults. Conclusion: This study therefore suggests that older adults should be encouraged to participate in some of these activities in order to ensure satisfactory support.
\end{abstract}

Keywords: Cultural activities, care-givers, inadequate support, older adults, south-east Nigeria.

\section{Introduction}

Increase in the population of older adults is a global experience as the numbers of older adults in many countries are increasing (Bélanger et al., 2016; Zimmer et al., 2016). The experience of population ageing is not unconnected with enhancement in living conditions, better nutrition and improved health care services in Nigeria (Mudiare, 2013; Omorogiuwa, 2016). Therefore, in Nigeria, ageing population is becoming increasingly visible with its significance challenges (Togonu-Bickersteth \& Akinyemi, 2014). The report of United Nations (20I2) revealed that Nigerians who are 60 years and older was 8.8 million in the year 2012 and this number is estimated to increase to 28 million by the year 2050. Thus, by this estimate, the proportion of older adults in Nigeria, will constitute about $10 \%$ of the total population by 2050. This suggests that the number of older adults will surpass the total population of some African countries like Ghana and Senegal in few years (Togonu-Bickersteth and Akinyemi, 20I4). On the other hand, Okoye (2012) asserts that Nigeria will likely experience increase in the number of older adults that depends on support systems consequent upon their withdrawal and frailty.

Scholars have reported some positive impacts of social support on older adults (Ahmad, 2016; Caetano et al., 20I3; Li et al., 20I4; Oluwagbemiga, 2016; Roh et al., 2015). Nevertheless, inadequate support systems hamper general security of older adults which manifests in their health condition and general well-being; also accounts for emotional breakdown such as depression which may eventually lead to death (Costa et al. 20I I; Lyyra and Heikkinen 2006; Melchiorre et al., 2013). For instance, older adults with inadequate support systems usually find it difficult to access health services; are susceptible to poor functional capacity and liable to develop some cardiovascular health issues (Caetano et al. 2013; White et al. 2009). According to Gow et al. (2007) insufficient social support is associated with poor cognitive abilities, lower life satisfaction and also responsible for higher levels of loneliness (Queen et al., 20I4). Poor cognitive functioning causes a huge upset to the well-being and daily life functioning of older adults (Johansson et al. 2015). Loneliness in old age is noted to be responsible for general poor health outcomes including anxiety, depression, mood and sleep disorder and also a crucial factor for risk behaviour such as substance abuse (Wilson and Moulton, 2010).

In lieu of the above, when older adults are adequately supported by various support systems, it will go a long way in achieving successful ageing. Several studies have shown that availability of social support can minimize the problems affecting the emotional, physical, social, economic, and psychological wellbeing of older adults. For instance, the study by Holt-Lunstad, Smith and Layton (2010) reveal that older adults with adequate social support have greater opportunities to survive from diseases such as cancer, cardiovascular disease, inflammation and less effective immune system functioning. Also, Evers et al. (2003) posit that social support helps 
older adults to cushion the effects of other diseases like functional disability and pains associated with arthritis. Supporting this view, Taylor (20II) noted that social support helps older adults reduce psychological distress such as anxiety or depression in stressful time.

In Nigeria, social support for older adults is informally inclined, usually provided by the families, community members and friends with little or no assistance from the government (Ogwumike and Aboderin, 2007; Oladeji, 20II; Sijuwade, 2008). Unlike in developed countries of Europe where all older adults are beneficiaries of state policies on social security system, many developing countries like Nigeria lack such provisions (Golaz and Rutaremwa, 20I I). Where efforts of the Nigerian government are lacking in providing social support for its older population (Okoye, 20I2; Fajemilehin and Odebiyi, 20II), dependence on the informal support systems especially the younger family members by these older adults becomes the order (Egunyomi, 2012). Traditionally, it is considered more a filial responsibility to provide for older adults in Nigeria (Ayodeji, 20I5; Animasahun and Chapman, 2017). Thus, assistance in terms of finance, healthcare, mobility, domestic chores, farming, etc., are provided by younger family members who might be spouse, children, son-in-law, daughter-in-law, sibling, nephew, niece, etc. This practice is seen normative to Nigerians across various tribes, religions, and geopolitical zones (Okoye, 20I2; Oladeji, 20II). However, factors of urbanization, industrialization and modernization have affected the extent to which these supportive measures were traditionally revered and easily accessed (Gesinde et al., 20I2; Okoye, 20/3). Hence studies have recorded inadequate social support for older adults in Nigeria and specifically in south-east Nigeria (Ebimgbo et al., 20I8a; Ebimgbo et al., 20।8b; Tanyi et al., 20l8). This current study therefore aims at discussing some cultural activities that can serve as social support system to older adults in south-east Nigeria. In doing this, the following research questions were raised: a) What are the cultural activities older adults participate in Nnewi, south-east Nigeria? 2) To what extent have these activities provided support to older adults?

\section{Literature review and theoretical framework}

Social support is accepted as a valuable resource comprising of tangible and intangible forms of assistance, welfare services that individuals receive from government, community, church, family and friends (Tang, 2008). According to McPherson and Wister (2008) the ideal support system involves different sources, formal and informal providing a combination of affective (emotional), psychological, and instrumental help when and where it is needed. A qualitative study by Kim, Kreps and Shin (2015) with 129 older adults revealed that friends, church members, and family members were the important network connections for Korean-Americans (KAs) to obtain health information, emotional support and companionship. Also, a study by Okumagba (20lI) with I 20 older adults who were 60 years and above revealed that older adults received support from family members, which include children, grandchildren and other relations within the extended family system. In the same vein, a survey by Johnston et al. (20I I) in Oklahoma which data were collected from 404 rural older adults who were 65 years and above and the results show that support from community members were significant predictors of an older adult's perceived sense of control. Osamor (2015) did a cross-sectional and descriptive study; data were collected from 440 older adults who were 60 years of age and the findings reveal that older adults receive social support from family members as well as their friends.

Furthermore, social support also entails different forms of financial help or in kind from state and other governmental institutions (Kokorić and Berc, 20I0). However, studies have revealed that Nigerian government has shown little or no support to older adults. Study by Shofoyeke and Amosun (20I4) found that there was no government support in the form of social security, health scheme, food, financial security as well as viable policy choices that support older adults in Nigeria. Also, Okunola (2002) and Ajomale (2007) aver that most Nigerian families take care of their older adults by seeing to their needs because the social security policies for older adults in Nigeria are just on paper. Thus, these analyses underscore the importance of participation in some cultural activities by older adults as a form of social support in order to improve their wellbeing.

Several factors have been found to influence the participation in social activities by older adult who will in turn translate to social support. They include gender, state of health, size of social network and income (Fajemilehin \& Odebiyi, 20 I I; Melchiorre et al. 20।3; Caetano, et al, 20l3; Ha et al., 20I5). Melchiorre et al. (2013) in qualitative study in Brazil with 3,649 older adults who were within the age range of 60 years and above found that older men spent less time alone and had less social interaction via participation in group activities but older women participated more in group activities and have larger social networks. The study by $\mathrm{Ha}$ et al. (20I5) equally revealed that older adults' poor health was associated with decreased positive interactions with friends. Also, Weyers et al (2008) revealed that reduced 
social networks and social participation are more frequent among older people with low socioeconomic position while Fajemilehin and Odebiyi (20I I) noted that older adults who receive lump sum of money every month will always relate more with family members and others, than those with small or no resources.

Social convoy model by Sherman, Wan and Antonucci (2015) posits that, individuals go through life embedded in a personal network of individuals from whom they give and receive social support. The convoy in this case is defined as a protective, dynamic network of close social ties that provide personal, familial, cultural, and even professional supports and linkages for an older adult. These social support which the individual (older adults in this case) receive are, associated not only with the well-being of the individual but also act as a buffer against certain risk factors such as physical and mental ill health.

Therefore, older adults that have strong social support networks tend to live happier and healthier lives. Several types of social support exist. They include; instrumental support (i.e., money and food), emotional support (i.e., offering care, counselling and comfort), informational support (i.e., providing advice, information and guidance), and esteem/appraisal support [i.e., affirming another person's sense of value, trust and competence] (Malecki and Demaray, 2003). Support networks may be informal e.g. family, relatives, friends, neighbours etc., or, formal e.g. healthcare providers, informal caregiver, non-governmental organisations, etc.

\section{Data and methods}

This study was conducted in Nnewi town south-east, Nigeria. Nnewi consists of four villages which include Otolo, Uruagụ, Umudim, and Nnewichi. Each village is usually divided into family units known as ụmụnna; meanwhile, each ưmunna is split into families with a first family known as the obi (Nwosu, 2016). The study area is geographically situated within the tropical rain forest region of Nigeria, which gives it the ecological basis for production of a wide range of tropical agricultural crops (Nnewi Union Atlanta, 2008). The main occupation of Nnewi people is trading and farming.

The choice of Nnewi town as the study area was informed by the fact that the area is grossly endowed with many cultural activities. Nnewi, as a historical city, has many cultural events and activities and is also adorned with festivities. Nnewi hosts many festivals and cultural events, notably amongst them are the new yam (Afịolụ or Ifejiọku) and ofala festival. Other activities in Nnewi that is grossly enshrined in the culture include marriages (traditional and church, postpartum, family meetings etc.). These festivals attract all sorts of activities and celebrations; equally they draw people from across the globe to partake in these activities. In most cases, older adults derive maximum support such as financial, emotional, material, and information support from them.

Cross-sectional survey design was adopted in this study. The researchers recruited 40 participants for the study and they were made up of 24 older adults and 16 caregivers. The researchers purposely selected eight older adults who were 60 years and above (four males and four females) for the In-depth Interview (IDI). This was informed by the policy thought in Nigeria that considers 60 years as the retirement age for civil servants. Four Focus Group Discussions (FGDs) were also conducted with older adults and their caregivers. The participants for the survey were older adults aged 60 years and above and their care-givers who were between the ages of 18 and 49. The focus group discussion consisted of two all-male groups and two all-female groups with eight participants in each group. In selecting the participants for the FGDs, the researchers were considerate regarding their age and sex; hence a group comprised of female older adults and another group comprised of female care-givers. More so, the same grouping process was employed in constituting male discussion groups. The eligibility criteria for selecting older adults was on the ground of residence; availability and willingness to partake in the discussion. Also, in selecting the care-givers, the researchers ensured that each care-giver abode with or provided support to either gender of older adults or both.

In selecting the participants for the FGDs, the researchers purposively selected two villages (Otolo and Uruagụ) from the study based on proximity and frail nature of some older adults; hence FGD with male older adult was conducted at Otolo while the discussion with the female older adult was carried out at Uruagụ. On the hand, the remaining two villages (Umudim and Nnewichi) were selected for the discussions with care-givers. While discussion for the male caregivers was carried out in Umudim, the discussion for the caregivers was performed at Nnewichi. In selecting the family units known as umunna for the discussions with older adults, the researchers utilized hand drawing method of simple random sampling to select two family units from each of the villages making it a total of eight family units selected for the study. The participants for the FGDs in each family unit were purposively selected on the premise of their availability.

For the in-depth interview with older adults, two participants (one male older adult and one female older adults) were selected in each of the villages. Simple random sampling technique was used to 
select a family unit in each village which was different from the units selected in FGD study. The eight participants were selected on their availability.

The field exercise was carried out in the year 2016 and lasted for two weeks. The study adopted qualitative methods in the data collection and analysis of the data. The instruments for data collection include IDI schedule and FGD guide. The IDI schedule and FGD guide contained unstructured questions to allow researchers probe for further questions which were not included in the interview and discussion but within the scope of the study. The discussion sessions lasted about 90 minutes while indepth interviews lasted about 40 - 50 minutes. One of the investigators moderated the interview and discussion sessions while the other investigators performed the role of note taking. The inductive thematic analysis developed by Braun and Clarke (2006) was adopted in the analyses of the transcripts and field notes. Responses from the IDIs and FGDs were recorded, alongside notes taken by a notetaker. The data were initially transcribed in the Igbo language and later translated verbatim into English to ensure exact meaning in both languages. The analysis of the transcripts was read overtime by researchers for familiarity and identification of common themes. The identified themes are: various forms of cultural activities which older adults are involved in and the extent to which older adults receive support from these activities. Thus, the final report on the findings was made upon these commonly identified themes.

Ethical considerations
The Ethical Review Board of the University of Nigeria, Nsukka approved the study instrument and methodology. Additionally, oral informed consent was sought and obtained from each participant before they were recruited for this study.

\section{Results}

The information on Table I indicates the background characteristics of the study respondents. From the information on the table, it seems there is equal proportions in gender of the respondents. From the data also, majority of the respondents $(60 \%)$ were between the ages of 60 and above while $40 \%$ of the respondents were between the ages of 18 to 49 years. It also appears that majority of the respondents $(62.5 \%)$ were married; this was followed by the respondents $(32.5 \%)$ who were widowed; only $5 \%$ were single as at the time of this study. This information may not be misleading since the focus of this study was on ageing; one expects that great chunks of the participants will be married adults. Going further, $30 \%$ of the respondents had no formal education, $30 \%$ had primary and secondary education while only 10\% had tertiary education. From the findings also, majority of the respondents $(72.5 \%)$ were self-employed; this was followed by the $10 \%$ of the respondents who were civil servants. These percentage of civil servants were mainly the care-givers because civil servants in Nigeria are expected to retire at the age of 60 years. The analysis indicated that $2.5 \%$ of the respondents reported to be unemployed while $7.5 \%$ were farmers and retirees.

Table I: Socio-demographic characteristics of respondents

\begin{tabular}{lll}
\hline Demographic data & Frequency & Percentage \\
\hline Sex & 20 & 50 \\
Male & 20 & 50 \\
Female & 16 & 40 \\
Age & 24 & 60 \\
I8-49 & & \\
$>60$ & 25 & 62.5 \\
Marital status & 13 & 32.5 \\
Married & 2 & 5 \\
Widowed & 0 & 0 \\
Single & & \\
Divorced & 12 & 30 \\
Education & 12 & 30 \\
None & 12 & 30 \\
Primary & 4 & 10 \\
Secondary & & \\
Tertiary & 1 & 2.5 \\
Occupation & 3 & 7.5 \\
None & 3 & 7.5 \\
Farming & & \\
Former employed & & \\
\hline
\end{tabular}




\begin{tabular}{lll}
\hline Self employed & 29 & 72.5 \\
Civil servant & 4 & 10 \\
\hline Soure: Fiedwo 2016
\end{tabular}

Source: Fieldwork 2016

\section{Various cultural activities and involvement by older adults Village meetings}

From the analysis of transcript, it appears that older adults are hugely involved in several meetings going on in their respective villages as all the participants acquiesced to this. Some of the participants indicated that older adults are often involved in village meetings while others stated that their opinion are always sought after in the meetings. Other respondents noted that older adults are highly knowledgeable in the culture of the community; hence their presence are always valued as they direct the younger ones. One of the female older adults in IDI conducted at Otolo said, "I usually attend village meetings with other women because they need me to guide them in certain decisions". Another female older adult in FGD conducted at Uruagu stated, "we were in a meeting before you [researchers] came in,". The opinion of a male older adult in an IDI conducted at Umudim was reflected in the quote below:

Of course, there is such activity in this community which we are often engaged in. We belong to several meetings involving the men alone; sometimes women and youths are involved. Even yesterday [Sunday], we had our family unit meeting [Nzuko ưmunna] at the village square. Next Sunday, we will still have another meeting that will comprise our family unit and two other family units [Ümu-okechi and Enemogo] which we called [Nzuko Akabor]. I am actively involved in all these activities because the young people want us there.

\section{Marriage ceremonies}

The researchers probed further to ascertain if older adults are involved in the marriage ceremonies going on the area. From the participants' responses, older adults partake in several marriage contractions. Some of the participants indicated that older adults must be present in traditional marriages; others noted that they [older adults] are equally presence during weddings especially church weddings because they are the ones that will guide how the kolanut will be shared before "prayers, breaking and eating". A male older adult in an IDI at Nnewichi stated: "I usually attend some social functions like traditional marriage, church wedding, although on invitation, because the people organizing the ceremony want me there". Meanwhile, an opinion of male participant in FGD conducted with care-givers at Umudim was reflected thus:
Older adults in our community are fully involved in every marriage ceremonies going on in this community. In fact, any social event or gathering such as wedding, traditional marriage in this community without the presence of older adults will look somehow because it will appear as if "they do not have people". They are the first people to beckon on before such events takes place since they know the rules and requirements. For instance, in any traditional marriage ceremony, wedding etc., the elders must be duly informed and they will help direct proceedings from their experience.

\section{Funerals ceremonies}

The analysis of transcript reveals that older adults are very much committed to burial and funeral activities. Majority of the participants indicated that older adults are usually the people to be informed when someone dies because they will know "who and who should be told first and advise the bereaved on what to do". Other respondents equally noted older adult are the ones that direct order of proceedings during funerals. One of the female older adults in FGD conducted at Uruagụ said:

We usually attend the funeral of any Nwa Okpu [any daughter that got married away from the family unit] that dies. We must spend some days with the family of the deceased before we can go back to our various homes. We help the younger "ụmu okpụ" to raise the right songs and dance steps and also ensure that our entitlements are not denied us.

A male older adult in FGD conducted at Otolo stated: Of course, "Keduzi ihe anyị nọ n' ụlọ alụ?" [What else are we doing in the village?]. We advise on the right burial site for any individual in the family that dies. That way, there will be no mistake that can cause trouble in future".

\section{Child naming/dedications}

The researchers probed to find out if older adults attend activities like child naming ceremonies or child dedications. From the responses of the participants, many older adults are actively participating in this form of activity. However, this form of activity is usually attended by older adults who are related to the family where such activity is taken place. Some of the participants noted that it is usually the duty of the older adult, especially the grandfather of the new born child, to name the child and bless him/her. A 
female caregiver in the FGD conducted at Nnewichi reflected, "my parents came around whenever I was dedicating my children. My father will always have a name for the child. My mother even came a day before the event to assist me. It was my father who came on the day of event". Another male caregiver in FGD conducted at Umudim narrated how his in-laws were presence in the naming ceremony and dedication of their children:

Yes, older adults in this community usually attend child dedications especially when any members of their families are involved. They use their experience to help make sure everything is in order. During the dedication of my children, my in-laws were there with other members of the family to celebrate with us. Even the last dedication of my twin babies some months ago, my mother-in-law came some days before the dedication with one of my sisters-in-law. The rest came on Sunday when the dedication and ceremony took place.

\section{Postpartum care}

The finding of the study also reveals that older female adult usually go for postpartum care of their female children that give births. However, all the participants in the discussions noted that this form of activity is often reserved for female older adults as men are culturally deprived of such activity. They also reported that the period provides opportunity for grand-mothers to bond with their grand-children and teach the new mother child rearing "formula". For instance, a male older adult in IDI conducted at Otolo said, "it is a must that women visit their female children whenever they give birth to babies to teach the girl how to care for her child, like bathing, carrying and breastfeeding the baby". Another female participant in FGD conducted with older adults at Uruagu said, "as culture demands, we have to go for omụgwọ [postpartum care] when our female children give birth to assist them in caring for the baby and some domestic work. That way we feel very useful and also contribute in training our grandchildren" They all noted that the rationale behind this is to help new mothers to cope with the stress associated with having a new child in the home.

Extent to which these activities yield the needed support to older adults

The researchers sought to find out the extent to which all these ongoing cultural activities in their various communities have been a source of social support to older adults. The responses from the participants indicated that with the exception of very few participants, majority accepted that these activities in their community have contributed immensely to their emotional support and well-being. Some of the participants indicated that opinions of the older adults are always sought and their presences are always valued whenever any of these activities take place. By this, the self-esteem of older adults is affected and they usually feel that they are still relevant in the society. Equally, other respondents reveal that older adults often have their fair share of proceeds from these activities in their respective communities. A female participant in an FGD conducted with older adults at Uruagu said this: "we often gather in a meeting like this; we are committed to it to solve some problems facing our families; we settle and resolve disputes among families". Other views of some participants are reflected in the following quotes: A male respondent in an IDI with older adults at Umudim said:

Yes! We are much involved in social activity because such support facilitates human interactions. Even, this is more prominent in this Igbo land. We do go for marriages, wine carrying, child naming ceremony. For instance, my last child got married some months back, we [me \& my wife] were there. He also sent a message to me for their child dedication at Cathedral of Good Shepherd Enugu which we must be there. You see, all these are supports and they promote social interaction.

In support of the views expressed earlier but from a different point, a male participant in FGD conducted with older adults at Otolo reflected thus:

Social activities that promote social support are very much prevalent in this community. Do you know that older adults do not always rest in this community as a result of so many social engagements? If it is not attending a meeting, it will be marriage. My children [the researchers] this is our duty and work in this community. During the traditional marriage ceremony, we are given special share of drink and meat if they killed a cow.

Very important finding of this study was that the analysis of transcript revealed that home-bound older adults are not exempted from these activities in their community. The study revealed that some of the participants stated that the home-bound older adults are duly informed about any event in the community; their shares [drinks, meat, kola nuts, money] from such events are also considered and reserved. For instance, the view of a female older adult in an IDI conducted at Otolo was reflected thus:

Yes, older adults who cannot go out again are also informed in most of the social activities going on in this community. No marriage ceremony or village 
meeting in this community will be successful without their knowledge because they may give suggestions. They are also beckoned on when there are difficult issues in the society that needs the opinion of the older people.

\section{Discussion}

The aim of this study was to describe some of the cultural activities in Nnewi, south-east Nigeria that serve social support systems for older adults. The finding of this study revealed that older adults usually participate in various cultural activities in their communities. These activities include village or family meetings, traditional wedding ceremonies, funerals among others. The findings show that these activities promote human interactions, relationships and serve as a form social support for the older adults. This implies that when the older adults come for such cultural events, it serves as an opportunity to not only interact and relate with other older adults, but with other people as well. This promotes their emotional wellbeing and helps them to build social networks.

Winstead et al. (20/4) noted that activity participation can provide older adults with opportunities for self-identification, an outlet to build social networks, an occasion for social interaction and an opportunity for role support, which are all important factors of successful aging. Also, Reitzes et al. (1995) found that participation in activities allows for interactions with others, which can impact a person's self-evaluation and self-esteem. Thiamwong et al. (20I3) in supporting the above finding noted that successful ageing is quite related to effective relationship with interactions between individuals and their social sphere or environment which include enjoyment through participating in community activities. Also, Yunong (20/2) revealed that social support was an important contributory factor to explaining life satisfaction among older people.

The study found that another reason why older adult participate in these cultural activities is because they want to guide the younger ones so as to be sure that the right things are being done. That way they ensure that the culture is passed on from one generation to the other. Lewis (20II) had noted in his study among older adults in Alaska that ensuring that traditional values andlifestyles were passed down to the next generation is seen as a parameter for successful aging. In other words, the participation of older adults in these cultural activities serves as an emotional social support for some of them. The study revealed that older adults not only participate in these activities but they often receive their fair shares of gifts and food in return thereby ensuring their adequate support and well-being. Also, some of the female older adults who participate in the postpartum care reported that it makes them feel useful. Lou (2010) in a study in Hong Kong reported that older adults get a lot of emotional support and appraisal support from their grandchildren. This is also true of the female older adults in this study.

Based on the findings from the present study, the social convoy model by Sherman, Wan and Antonucci (20I5) can be used by social workers to assess the ability of an older adult to cope with their daily living, and to evaluate the importance of social participation in cultural activities to the wellbeing of an older adult. Changes that occur over time can be explored to see the effects of lack of participation on the individual, as social networks may grow in some areas and shrink in others as a result of death of people in the network and ill health. This can also inform policy decisions in the long run.

\section{Conclusion}

This study aimed at depicting some cultural activities as a measure of social support systems for older adults in Nnewi south-east Nigeria. Participating in cultural activities were found to be veritable source of social support to older adults. This study therefore suggests that older adults should be encouraged to participate in these cultural activities in their villages in order to ensure that they live meaningful lives. Also, family members or care-givers of older adults should always ensure that older adults participate actively in most of these activities in their communities. This could be attained by assisting them to the venues of events and equally assist them back to their various homes. Engaging older adults in some of these events to a great extent affords them the opportunity to use their experience, skills, and knowledge acquired in their active phase of life as a cost-effective strategy to imbue communities and improve the quality of life across the life course, and promote successful and healthy aging for future generations (Ghazi et al., 2017).

\section{References}

Ahmad, A. (2016). Life Satisfaction versus Social Support among Aged: An Overview. Psychology and Behavioral Science International Journal, [online] I(4), pp. 00I-005. Available at: http://www.juniperpublishers.com >pbs.

[Accessed 6 Dec. 2014].

Ajomale, O. (2007). Country Report: Ageing in Nigeria-Current State, Social and Economic Implications. African Gerontological Society. Available at: http://rcllsociology-ofaging.org/system/files/Nigeria\%202007_0.pdf.

[Accessed 16 Jan. 20I5].

Animasahun, V. J. and Chapman, H. J. (2017). Psychosocial Health Challenges of the Elderly in 
Nigeria: A Narrative Review. African Health Science, I7(2), pp. 575 - 583.

Ayodeji, A. M. (20I5). Protecting the Rights of Old People in Nigeria: Towards a Legal Reform. Journal of Law, Policy and Globalization, [online] 40, pp. |3|-|43. Available at: http://www.iiste.org/Journals/

index.php/JLPG/.../25450. [Accessed 22 Mar. 2017].

Bélanger, E., Ahmed, T., Vafaei, A., Curcio, C. L., Philips, S. P. and Zunzunegui, M. V. (2016). Sources of Social Support Associated with Health and Quality of Life: A Cross-Sectional Study Among Canadian and Latin American Older Adults. BMJ Open, 6, pp. I-IO. Available at: http://bmjopen.bmj.com/

content/bmjopen/6/6/e0I I 503.full.pdf. [Accessed 27 Mar. 2017].

Braun, V. and Clarke, V. (2006). Using Thematic Analysis in Psychology. Qualitative Research in Psychology, 3, 77-I0I.

Caetano, S. C., Silver, C. M. F. P. and Vettore, M. V. (2013). Gender Differences in the Association of Perceived Social Support and Social Network with Self-Rated Health Status Among Older Adults: A Population-Based Study in Brazil. Boston Medical Center Geriatrics, [online] 13, p. 122. Available at: http://www.biomedcentral. com //47I23/8/I3/I22. [Accessed 16 Jun. 2016].

Costa, S. V., Ceolim, M. F. and Neri, A. L. (20II). Sleep Problems and Social Support: Frailty in a Brazilian Elderly Multicenter Study. Revista LatinoAmericana de Enfermagem, 19(4), pp. 920-927.

Ebimgbo, S. O., Atumah, O. N. and Okoye, U. O. (20|8a). Church-Based Organisatons and their Role in the Support of Older Adults in Nnewi, South-East Nigeria. African Population Studies, [online] 32(2), pp. 4203-42/4. Available at: http://aps.journal.ac.za. [Accessed 27 Sep. 2018]

Ebimgbo, S. O., Atumah, O. N. and Okoye, U. O. (2018b). Policy Implication of Inadequate Social Support Systems for Older Adults in Nnewi LGA, Anambra State. Nigerian Journal of Public Administration and Local Government, 19(I), pp. 109-127

Egunyomi, D. A. (2012). The Adults and Aged: The Nigerian Situation. In H. O. Osinowo, O. A. Moronkola and D. A. Egunyomi (Eds.), The Adults and Aged in Nigeria: Issues and Researches (pp. I16). Ibadan: Royal People Nig. Ltd.

Evers, A. W. M., Kraaimaat, F. W., Geenen, R., Jacobs, J. W. G. and Bijlsma, J. W. J. (2003). Pain Coping and Social Support as Predictors of LongTerm Functional Disability and Pain in Early Rheumatoid Arthritis. Behaviour Research and Therapy, 3, 1295-1310.
Fajemilehin, B. R. and Odebiyi, A. I. (20II). Predictors of Elderly Persons' Quality of Life and Health Practices in Nigeria. International Journal of Sociology and Anthropology, [online] 3(7), pp. 245-252. Available at: http://www.academicjournals.org/ IJSA. [Accessed 28 Jun. 20I6].

Gesinde, A. M., Adekeye, O. A. and Iruonagbe, T. C. (20/2). Poverty and Old Age: The Nigerian Situation. In H. O. Osinowo, O. A. Moronkola and D. A. Egunyomi (Eds.), The Adults and Aged in Nigeria: Issues and Researches (pp. 127-144). Ibadan: Royal People Nig. Ltd.

Ghazi, H. F., Sutan, R., Elnajeh, M., AbdalQader, M. A. and Baobaid, M. F. (2017). The Importance of Social Participation and Networking Among Elderly People: Short Review. Journal of Management and Science, [online] I5(I), pp. 99107. Available at: https://www.researchgate.net/publication/3 I 738I 572_The_importance_of_social_participation_and _networking_among_elderly_people_short_revie w. [Accessed 21 Jan. 2019].

Golaz, V. and Rutaremwa, G. (20II). The Vulnerability of Older Adults: What do Census Data Say? An Application to Uganda. African Population Studies, [online] 25(2), pp. 605-622. Available at: aps.journals.ac.za/pub/article/view/248. [Accessed 30 Oct. 2018].

Gow, A., Pattie, A., Whiteman, M., Whalley, L. and Deary, I. (2007). Social Support and Successful Aging: Investigating the Relationships Between Lifetime Cognitive Changes and Life Satisfaction. Journal of Individual Differences, 28(3), I03-II 5.

$\mathrm{Ha}$, J-H., Kahng, S. K. and Choi, N. (20I5). Reciprocal Effects Between Health and Social Support in Older Adults' Relationships with their Children and Friends. Researching on Aging, [online] 39(2), pp. 275-299. Available at: http://journals.sagepub.com/toc/roaa/39/2.

[Accessed 26 Dec. 2018].

Hata, K., Inayama, T., Matsushita, M. and Shinoda, S. (2016). The Combined Associations of Social Participation and Support with Self-Rated Health and Dietary Satisfaction in Men with Spinal Cord Injury. Spinal Cord, 54, pp. 406-10.

Holt-Lunstad, J., Smith, T. B. and Layton, J. B. (20I0). Social Relationships and Mortality Risk: A MetaAnalytic Review. Publication Library of Science Medicine, [online] 7, pp. I-2I. Available at: http://www.scholarsarchive.byu.edu/cgi/viewcont ent.cgi?article $=1093 \&$ context $=$ facpub\# [Accessed I 2 June 20I6]

Johansson, M. M., Marcusson, J. and Wressle, E. (20I5). Cognitive Impairment and Its 
Consequences in Everyday Life: Experiences of People with Mild Cognitive Impairment or Mild Dementia and their Relatives. Int. Psychogeriatrics, 27, pp. 949-958.

Johnston, J. H., Brosi, W. A., Hermann, J. R. and Jaco, L. (20II). The Impact of Social Support on Perceived Control Among Older Adults: Building Blocks of Empowerment. Journal of Extension, [online] 49(5), pp. I-8. Available at: http://www.joe.org/joe/ 20l loctober/pdf/ JOE_ 49_5rb4.pdf. [Accessed 8 Apr. 2016].

Kim, W., Kreps, G. L. and Shin, C. N. (2015). The Role of Social Support and Social Networks in Health Information-Seeking Behavior Among Korean Americans: A Qualitative Study. International Journal for Equity in Health, [online] I4(I), p. 40. Available at: http://www.equity healthj.com/content//4/I/40\#sec3. [Accessed 16 Jan. 20I5].

Kokorić, S. B. and Berc, G. (2010). Satisfaction With Life and Informal and Formal Sources of Support Among People with Disabilities. Available at: http://www.Silvia

RUSAChrcak.srce.hr/vindex.php?show = clanak\&id _clanak_jezik=...Cached. [Accessed I 4 Jan. 20 I7].

Lewis, J. P. (20II). Successful Aging Through the Eyes of Alaska Native Elders. What it Means to be an Elder in Bristol Bay, AK. The Gerontologist, $5 \mathrm{I}$ (4), pp. 540-549.

Li, H., Ji, Y. and Chen, T. (20/4). The Roles of Different Sources of Social Support on Emotional Well-Being Among Chinese Elderly. PLoS ONE, [online] 9(3), pp.I-8. Available at: http://www. flosone.org/articles/info\%3Adoi\%2FI0.137/\%2Fj ournal.pone.009005I. [Accessed $22 \mathrm{Dec}$. 20I6].

Lou, V. W. (20I0). Life Satisfaction of Older Adults in Hong Kong: The Role of Social Support from Grandchildren. Social Indicators Research, 95(3), pp. 377-39l.

Lyyra, T. M. and Heikkinen, R. L. (2006). Perceived Social Support and Mortality in Older People. Journal of Gerontology. Serial B, Psychological Sciences and Social Sciences, 61, pp. I47-I52.

Malecki, C. K. and Demaray, M. K. (2003). What Type of Support Do They Need? Investigating Student Adjustment as Related to Emotional, Information, Appraisal, and Instrumental Support. School Psychology Quarterly, 18, pp. 23I-252.

McPherson, B. D. and Wister, A. (2008). Aging as a Social Process Canadian Perspectives. Ontario: Oxford University Press.

Melchiorre, M. G., Chiatti, C., Lamura, G., TorresGonzales, F., Stankunas, M., Lindert.J..., Soares, J. F. (20I3). Social Support, Socio-Economic Status, Health and Abuse Among Older People in Seven European Countries. PLoS ONE, [online] 8(I), pp.
I-10. Available at: http://www.ncbi.nlm.nih.gov /pmc/articles/PMC3559777/ [Accessed 19 Feb. 2015].

Mudiare, P.E.U. (20/3). Abuse of The Aged in Nigeria: Elders Also Cry. American International Journal of Contemporary Research, 3(9),pp. 7987.

Nwosu, O. E. (2016). Brief History of Nnewi. [online]. Available at: http://www.nnewichamber of commerce.com/about... [Accessed Jan. 31, 2019].

Ogwumike, F. O. and Aboderin, I. (2007). Exploring the Links Between Old Age and Poverty in Anglophone West Africa: Evidence from Nigeria and Ghana. Generations Review, I5(2), pp. 7-I5.

Okoye, U. O. (20/3). Community-Based Care for Home Bound Elderly Persons in Nigeria: A Policy Option. International Journal of Innovative Research in Science, Engineering and Technology, 2(I2), pp. 7089-709।.

Okoye, U. O. (20/2). Family Care-Giving for Ageing Parents in Nigeria: Gender Differences, Cultural Imperatives and the Role of Education. International Journal of Education and Ageing, 2(2), pp. 139-154.

Okumagba, P. O. (20II). Family Support for the Elderly in Delta State of Nigeria. Studies on Home and Community Science, [online] 5(I), pp. 2I-27. Available at: http://www. Krepublishers.com/.../HCS-05-I-02 I I-I46.

[Accessed I7 Feb. 20I7].

Okunola, M. I. (2002). Old Age Care. A Hand Book for Nigerian Social Workers. Ibadan: Daybis Ltd.

Oladeji, D. (20I I). Family Care, Social Services, and Living Arrangements Factors Influencing Psychosocial Well-Being of Elderly from Selected Households in Ibadan, Nigeria. Education Research International, [online] 20II, pp. I-6. Available at: http://www. hindawi.com/journals/edri/201 I/421898/

[Accessed 18 Nov. 2014].

Oluwagbemiga, O. (2016). Effect of Social Support Systems on the Psychosocial Well-Being of theElderly in Old People's Homes in Ibadan. Journal of Gerontology \& Geriatric Research, [online] 5(5), I-9. DOI: 10.4I72/2।677182.1000343 [Accessed 28 Sep. 2017].

Omorogiuwa, T.B.E. (2016). The Psychosocial Problems of the Elderly: Implications for Social Work Practice. Journal of Nursing, Social Studies, Public Health and Rehabilitation [online] 3-4, pp. I I I-I I 8. Available at: casopis-zsfju.zsf.jcu.cz , ... , $2016>$ num.3-4. [Accessed 28 Jan. 20I7].

Osamor, P. E. (20/5). Social Support and Management of Hypertension in South-West Nigeria. Cardiovascular Journal of Africa, [online] 
26(I), pp. 29-33. Available at: http://www.ncbi.nlm .nih.gov/pmc/ articles/PMC4392208/ [Accessed 25 Apr. 2015].

Queen, T. L., Stawski, R. S., Ryan, L. H. and Smith, J. (2014). Loneliness in a Day: Activity Engagement, Time Alone, and Experienced Emotions. Psychol Aging. [online] 29(2), pp. 297-305. PMid:24955998. Available at: http://dx.doi.org//0.1037/a0036889. [Accessed 22 Aug. 20I6].

Reitzes, D. C., Mutran, E. J. and Verrill, L.A. (1995). Activities and Self-Esteem: Continuing the Development of Activity Theory. Research on Aging, [online] 17(3), pp. 260-277. Available at: http://search.proquest.com/docview/6|400886 [Accessed I 2 Jan. 20I9].

Roh, S., Kim, Y., Lee, K. H., Lee, Y., Burnette, C. E. and Lawler, M. J. (20I5). Religion, Social Support, and Life Satisfaction among American Indian Older Adults. Journal of Religion \& Spirituality in Social Work: Social Thought, [online] 34(4), Available at: http://www.academic.oup.com > gnrl03

[Accessed I 8 Dec. 20I7].

Sherman, C. W., Wan, W. H. and Antonucci, T. C. (2015). Social Convoy Model. The Encyclopedia of Adulthood and Aging, (I-5) Hoboken, NJ: John Wiley \& Sons, Inc.

Shofoyeke, A. D. and Amosun, P. A. (20I4). A Survey of Care and Support for the Elderly People in Nigria. Mediterranean Journal of Social Sciences, [online] 5(23), pp. 2553-2563. Available at: www.mcser.org/journal/index.php/mjss/article/vie wFile/.../4674. [Accessed I6 Jun. 20I7].

Sijuwade, P. O. (2008). Elderly Care by Family Members: Abandonment, Abuse and Neglect. The Social Sciences, 3(8), pp. 542-547.

Tang, Y. (2008). Social Support of Elderly Caregivers. International Journal of Business and Management, [online] 3(8), pp. 8I-84. Available at: http://www.ccsent.org/journal /index.php /ijbm/ article/viewFile/.../I 275. [Accessed 20 Jul. 20 I5].

Tanyi, P. L., André, P. and Mbah, P. (2018). Care of the Elderly in Nigeria: Implications for Policy. Cogent Social Sciences, 4, I55520I.

Taylor, S. E. (20I I). Social Support: A Review. In M. S. Friedman (Ed.), The Handbook of Health Psychology (pp. 189-214). New York: Oxford University Press.
Thiamwong, L., McManus, M. S. and Suwanno, J. (20/3). Development of the Thai Healthy Aging Model: A Grounded Theory Study: Thai Healthy Aging Model. Nursing \& Health Sciences, 15(2), pp. 256-26I

Togonu-Bickersteth, F. and Akinyemi, A. I. (20I4). Ageing and National Development in Nigeria: Costly Assumptions and Challenges for the Future. African Population Studies, [online] 27(2), pp. 36I-37I. Available at: http://aps.journals.ac.za/pub/article/view/48I [Accessed 10 Nov. 20I7].

United Nations, Department of Economic and Social Affairs, Population Division. (20I2). World Population Prospects: The 2010 Revision. [Online] Available at: http://www.un.org /esa/population/publications/20 I 2WorldPopAgeing Dev_Chart/2012PopAgeing and Dev WallChart.pdf. [Accessed I5 Aug. 2015].

Wilson, C. and Moulton, B. (2010). Loneliness Among Older Adults: A National Survey of Adults 45+. Prepared by Knowledge Networks and Insight Policy Research. Washington, DC: AARP

Wilson, R. S., Krueger, K. R., Arnold, S. E., Schneider, J. A., Kelly, J. F., et al. (2007). Loneliness and Risk of Alzheimer Disease. Arch Gen Psychiatry, 64, pp. 234-240. PMID: I728329|

Winstead, V., Yost, E. A., Cotten, S. R., Berkowsky, R. W. and Anderson, W. A. (20I4). The Impact of Activity Interventions on the Well-Being of Older Adults in Continuing Care Communities. The Journal of Applied Gerontology, [online] 33(7), pp. 888-9। I. Available at: http://dx.doi.org/10.1। 77 /07334648 I453770 I

Yunong, H. (20/2). Family Relations and Life Satisfaction of Older People: A Comparative Study Between two Different Hukous in China. Ageing \& Society, 32(I), pp. 19-40.

Zimmer, Z., Jagger, C., Chiu, C-T., Ofstedal, M. B., Rojo, F. and Saito, Y. (20|6). Spirituality, Religiosity, Aging and Health in Global Perspective: A Review. SSM-Population Health, [online] 2, pp. 373-38I. Available at: https://ac.elscdn.com/S2352827316300 I79/I-s2.

S23528273 I6300 I 79-main.pdf?_tid=9ac0997aa38I-Ile7-904b-00000aa [Accessed 27 Nov. 2017]. 